\title{
Cationic Ring Opening Polymerization of e-caprolactam by a Montmorillonite Clay Catalyst
}

\author{
Djamal Eddine Kherroub ${ }^{\text {*, }}$, Mohammed Belbachir ${ }^{1}$, Saad Lamouri ${ }^{2}$ \\ ${ }^{1}$ Laboratoire de chimie des polymères, Département de Chimie, Faculté des Sciences, Université \\ d'Oran, BP 1524 El'Menouer Oran 31000, Algérie \\ ${ }^{2}$ Laboratoire de Chimie Macromoléculaire, Ecole Militaire Polytechnique (EMP), Bordj El Bahri, \\ 16111 Alger, Algérie
}

Received: 3rd October 2013; Revised: 28th February 2014; Accepted: 1st March 2014

\begin{abstract}
The ring opening bulk polymerization of $\varepsilon$-caprolactam catalyzed by Maghnite- $\mathrm{H}^{+}$was reported. Maghnite- $\mathrm{H}^{+}$is a montmorillonite silicate sheet clay was prepared through a straight forward proton exchange process. The effect of the amount of catalyst, and temperature was studied. Increasing Maghnite- $\mathrm{H}^{+}$proportion and temperature produced the increase in $\varepsilon$-caprolactam conversion. The kinetics indicated that the polymerization rate is first order with respect to monomer concentration. Mechanism studies showed that monomer inserted into the growing chains with the acyl-oxygen bond scission rather than the break of alkyl-nitrogen bond. C 2014 BCREC UNDIP. All rights reserved
\end{abstract}

Keywords: Maghnite-H+; Montmorillonite; $\varepsilon$-Caprolactam, Ring opening polymerization

How to Cite: Kherroub, D.E., Belbachir, M., Lamouri, S. (2014). Cationic Ring Opening Polymerization of $\varepsilon$-caprolactam by a Montmorillonite Clay Catalyst. Bulletin of Chemical Reaction Engineering \& Catalysis, 9 (1): 74-79. (doi:10.9767/bcrec.9.1.5555.74-80)

Permalink/DOI: http://dx.doi.org/10.9767/bcrec.9.1.5555.74-80

\section{Introduction}

Nylon is the first commercialized synthetic fiber, which is used throughout the world such as wearing apparel, brush bristles, and carpet because of its good properties [1,2]. Poly ( $\varepsilon-$ caprolactam) usually known as (nylon 6 or Polyamide 6) are an attractive class of nylons, and have been applied very widely due to their excellent tensile properties, low friction, high melting point, and chemical and wear resistance $[3,4,5]$, it is synthesized by ring open-

* Corresponding Author.

E-mail: djamaleddine.kherroub@yahoo.com (D. Kherroub), Tel: +213795565299, Fax: +21341581413 ing polymerization of $\varepsilon$-caprolactam. The cationic polymerization of $\varepsilon$-caprolactam and its reaction mechanism has been studied for many years in the presence of cationic initiators [611]. Various strong protonic acids able to promote the polymerization of $\varepsilon$-caprolactam have been reported [12-18]. The separation of the initiators from the polymer is not always possible. Therefore, the presence of toxic initiators presents problems in the manufacture of polymers used especially in medical and veterinary procedures.

There is still a great demand for heterogeneous catalysis under mild conditions and in environmentally friendly processes. Montmorillonites, a class of inexpensive and noncorrosive solid acids, have been used as efficient catalysts 
for a variety of organic reactions. The reactions catalyzed by montmorillonites are usually carried out under mild conditions with high yields and high selectivities, and the workup of these reactions is very simple; only filtration to remove the catalyst and evaporation of the solvent are required, maghnite- $\mathrm{H}^{+}$can be easily recovered and reused, after it has separated from the polymer, it was rinsed with water and dried by heating to a temperature above $100{ }^{\circ} \mathrm{C}$ and finally crushed [19, 20]. To ensure good performance, the Maghnite- $\mathrm{H}^{+}$can be reactivated with acid [21,22].

The novelty of this work is to propose a greener and more sustainable route in order to replace the hazardous acidic catalysts such as: $\mathrm{H}_{3} \mathrm{PO}_{4}[12,17]$ and $\mathrm{HCl}$ [18] by modified clay of our region (Maghnite- $\mathrm{H}^{+}$) for the synthesis of polyamide 6 , a new, non-toxic cationic catalyst for heterocyclic monomers [23], which is widely available, constitutes low costs and has excellent properties make it the subject of several research. The obtained results will be compared with those obtained previously with strong acids.

Techniques such as Infra Red (IR), Differential Scanning Calorimetry (DSC), Hydrogen and Proton Nuclear Magnetic Resonance ( ${ }^{1} \mathrm{H}$ NMR and ${ }^{13} \mathrm{C} \mathrm{NMR}$ ), were used to characterize the products of the reaction. The effects of catalyst/ monomer weight ratio and time on monomer conversion and polymer average molecular weight were also examined.

\section{Materials and Methods}

\subsection{Materials}

The $\varepsilon$-caprolactam (grade 99\%) was used as purchased from Aldrich chemical. Diethyl ether and tetrahydrofuran were distilled over the blue benzophenone-Na complex. Formic acid (from Merck) used in all experiment was suprapure quality. Methanol was dried over magnesium sulphate $\mathrm{MgSO}_{4}$ and distilled. RawMaghnite: Algerian montmorillonite clay was procured from BENTAL (Algerian Society of Bentonite).

\subsection{Preparation of Maghnite- $\mathrm{H}^{+}$}

Maghnite- $\mathrm{H}^{+}$was prepared according to the process reported in our previous study [21,22]. Raw-Maghnite (20 g) was crushed for $20 \mathrm{mn}$ using a prolabo ceramic balls grinder. It was then dried for $2 \mathrm{~h}$ at $105^{\circ} \mathrm{C}$. The Maghnite was placed in an Erlenmeyer flask together with $500 \mathrm{ml}$ of distilled water. The Maghnite/water mixture was stirred using a magnetic stirrer and combined with $0.25 \mathrm{M}$ sulfuric acid solution, until saturation was achieved over 2 days at room temperature, the mineral was then washed with distilled water to became sulfate free and then dried at $105^{\circ} \mathrm{C}$, a test of the barium nitrate of the residue of rinsing water is needed to ensure that the sulfate is eliminated.

\subsection{Procedures and Polymer Characteri- zation Kinetics Procedure}

The ring-opening bulk polymerization (i.e. in absence of solvent) of $\varepsilon$-caprolactam was carried out into a small Teflon tube, previously flushed with nitrogen, the tube was placed inside the reactor vessel which was lightly closed. The tube contains a mixture of $1.13 \mathrm{~g}$ (10 mmol) of $\varepsilon$-caprolactam and an amount of Maghnite- $\mathrm{H}^{+}$. The weight ratio Maghnite$\mathrm{H}^{+} /$monomer was kept constant (at the desired value) for all experiences at different temperatures. Conversion was determined by grinding of polymer extracting in Soxhlet for $16 \mathrm{~h}$ with methanol for several times. The insoluble material was dried at $85{ }^{\circ} \mathrm{C}$ in vacuum for $8-10 \mathrm{~h}$ and weighed as polymer. The extracting methanol was then evaporated and the residue was extracted with diethyl ether. It was then assumed that the ether-soluble material was monomer and that oligomers formed the etherinsoluble material [24].

\subsection{Polymer Characterization}

IR absorption spectrum was recorded on an ATI Matson FTIR No 9501165 spectrometer, the sample is prepared by cutting the appropriate amount using scissors which have been previously cleaned. It is then sprinkled into a matrix of $\mathrm{KBr}$, and it is ground in an agate mortar. When a homogeneous mixture has been obtained it is compressed by applying a pressure of 10 tones. In this way a compressed disc is obtained which can be used to allow the corresponding spectrum.

The thermal behavior was investigated using a Setaram 92 DSC instrument. The specimen (approximately $8 \mathrm{mg}$ ) is placed into a standard aluminum sample pan, is then heated at a rate of $10{ }^{\circ} \mathrm{C} / \mathrm{min}$ from 20 to $300{ }^{\circ} \mathrm{C}$. It is important to use a dry nitrogen purge (50 $\mathrm{mL} / \mathrm{min}$ ) to avoid oxidative degradation while heating, the sample is then cooled back to $20^{\circ} \mathrm{C}$ at a rate of $10^{\circ} \mathrm{C} / \mathrm{min}$. The thermal parameters such as melting temperature (Tm) and heat of fusion $\left(\Delta \mathrm{H}_{\mathrm{f}}\right)$ were determined from the corresponding transitions in the DSC thermogram.

Measurements of ${ }^{1} \mathrm{H}$ and ${ }^{13} \mathrm{C}$ NMR spectra 
molecular weight of polymer reach maximum values around $240-250{ }^{\circ} \mathrm{C}$. On the other hand, with the increase in the reaction temperature above $250{ }^{\circ} \mathrm{C}$ the molecular weight of the obtained polymer and monomer conversion decrease progressively suggesting the possible occurrence of thermal degradation. It can be noted that above $260{ }^{\circ} \mathrm{C}$, molecular weight distribution of the resulting polymer was broad suggesting the occurrence of thermal degradation of the polymers at the reaction temperature over $250^{\circ} \mathrm{C}$. On the basis of these results, subsequent polymerizations were carried out at $250^{\circ} \mathrm{C}$.

\subsection{Effect of Maghnite- $\mathrm{H}^{+} / \mathrm{Monomer}$ weight ratio}

Figures 3 and 4 show the effect of Maghnite/ Monomer weight ratio on the Conversion of e-caprolactam and molecular weight of the polymer respectively. Indeed, using various amounts of Maghnite- $\mathrm{H}^{+}, 2,5,10$, and $15 \%$ by weight, the polymerization of $\varepsilon$-caprolactam

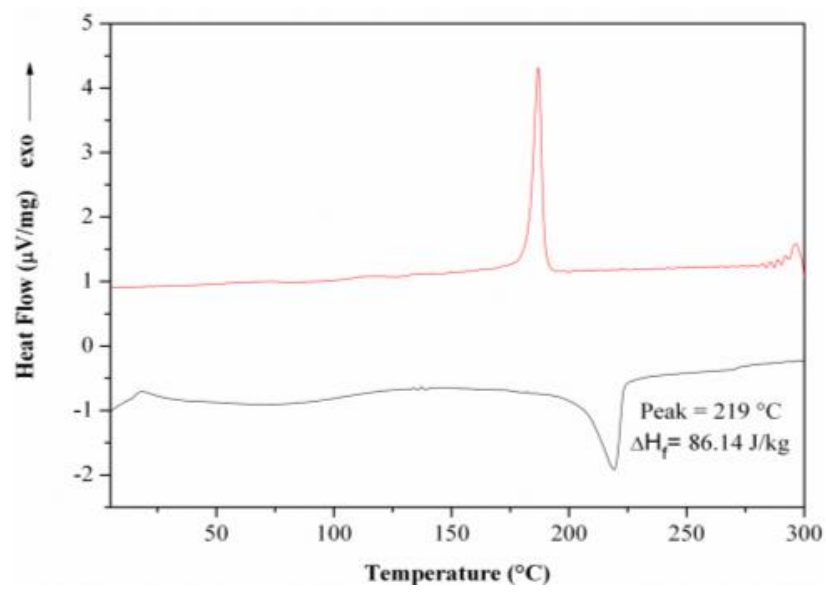

Figure 2. DSC thermogram of poly ( $\varepsilon$ caprolactam) product of the reaction

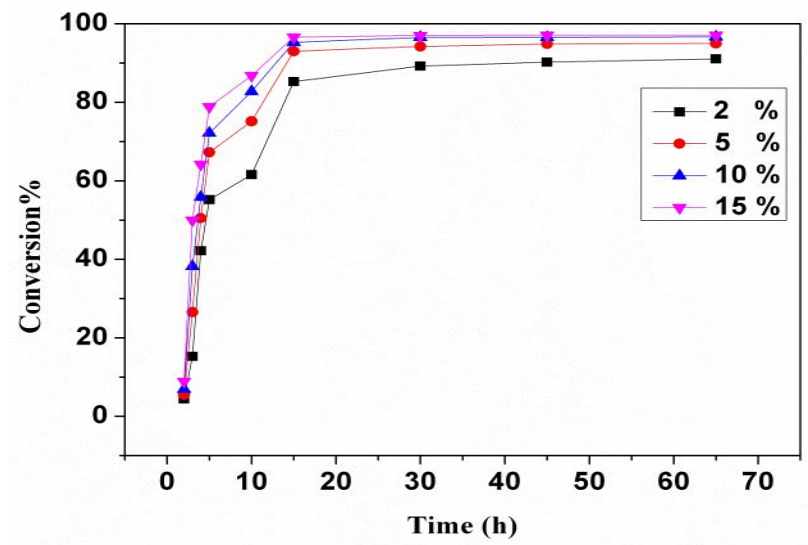

Figure 3. Effect of Maghnite- $\mathrm{H}^{+} /$Monomer weight ratio on the conversion of Monomer was carried in bulk at $250{ }^{\circ} \mathrm{C}$. It can be noted that increasing in weight ratio Maghnite- $\mathrm{H}^{+} / \varepsilon$ caprolactam increases the conversion of monomer to polymer and decreases the molecular weight of the resulting polymer. This result shows the effect of Maghnite- $\mathrm{H}^{+}$as a cationic catalyst. Similar results are obtained by Belbachir et al. [14,23,29] in the polymerization of $\varepsilon$-caprolactone by Maghnite- $\mathrm{H}^{+}$, which polymerizes only by cationic process [30].

Polymerization using a weight ratio Maghnite- $\mathrm{H}^{+} / \varepsilon$-caprolactam of $5 \%$ was carried out at $250{ }^{\circ} \mathrm{C}$ and the reaction was monitored at various times to study the evolution of monomer conversion and the molecular weight of the polymer with reaction time. The results are given in Table 2.

The molecular weight increases with polymerization time and reaches a maximum after $15 \mathrm{~h}$. The results show that between 3 and $15 \mathrm{~h}$, molecular weight increases gradually and after $30 \mathrm{~h}$, it decreases. This result suggests that intramolecular transesterification, i.e. "back-biting", which causes degradation and formation of cyclic oligomers and consequently may cause a decrease of the molecular weight $[31,32,33]$. On the other hand, the monomer conversion increase with the time and it can be noted that initially the polymerization proceeds very slowly; this can be considered as an induction period $(2 \mathrm{~h})$, which consumed approximately $5 \%$ of the monomer. At the end of this period, the polymerization process becomes faster.

Table 1. Effect of reaction temperature on the $\varepsilon$-caprolactam polymerization a

\begin{tabular}{cccc}
\hline$T\left({ }^{\circ} \mathrm{C}\right)$ & $\begin{array}{c}\text { Conversion of } \\
\text { Monomer (wt\%) }\end{array}$ & $M_{V} \times 10^{-4}$ & $M_{w} / M_{n}$ \\
\hline 220 & 68.89 & 2.54 & 1.56 \\
230 & 86.25 & 2.97 & 1.84 \\
240 & 90.54 & 5.00 & 1.77 \\
250 & 93.13 & 5.19 & 1.80 \\
260 & 86.66 & 4.01 & 1.73 \\
270 & 82.78 & 3.88 & 1.71 \\
280 & 77.12 & 2.13 & 1.66 \\
\hline a Maghnite-H+/e-caprolactam weight ration $=5 \%$. \\
Reaction time 15 h. \\
$M_{v}:$ The Viscosity Average Molecular Weight. \\
$M_{n}$ : The Number Average Molecular Weight. \\
$M_{w}:$ The Weight Average Molecular Weight. \\
$M_{w} / M_{n}$ : polydispersity index (PDI).
\end{tabular}


were conducted by dissolving the sample in 2,2,2-trifluoroethanol with heating, then adding $\mathrm{CDCl}_{3}$ to the cooled solution to give a fraction 10-20 wt\% of polymer in solvent mixture consisting of $4: 1$ ration of TFE to $\mathrm{CDCl}_{3}$, under ambient temperature, on a Bruker AC 250 instrument using tetramethylsilane (TMS) as internal standard.

\subsection{Viscosity and Molecular Weight}

Viscosity measurements were carried out with an Ubbelohde capillary viscosimeter (viscologic TI1, version 3-1 Semantec). Intrinsic viscosity, $[\eta](\mathrm{ml} / \mathrm{g})$, was measured at $25^{\circ} \mathrm{C}$ in Formic acid. Viscosity - average molecular weight, $M_{v}$, was calculated according to the following equation [18]:

$$
[\eta]=6.63 \times 10^{-5} \times M_{v}^{0.94}
$$

Gel-permeation chromatography was performed with a Spectra-Physics chromatograph, equipped with four columns connected in series, and packed with Ultrastyragel $10^{3}, 10^{4}$, $10^{5}, 10^{6} \AA$. THF was used as solvent and the instrument was calibrated to a first approximation with polystyrene of known molecular weights.

\section{Results and Discussion}

Montmorillonites have both Brönsted and Lewis acid sites and when exchanged with cations having a high charges density, as protons, produce highly active catalysts for acidcatalysed reactions [25]. Intercalated organic molecules are mobile and can be highly polarized when situated in the space between the charged clay layers. These exchanged montmorillonites have been successfully used as catalysts for the reactions of polymerization [26]. The present study is also concerned with polymerization and examines the catalytic activity of an Algerian proton exchanged montmorillonite clay called "Maghnite" via $\varepsilon$ caprolactam polymerization. The aim of this research is to extend the scope of other promising new field of polymer synthesis by the use of another catalyst system that has been shown to exhibit higher efficiency.

\subsection{Ring-opening Polymerization of $\varepsilon-$ caprolactam}

The $\varepsilon$-caprolactam is well known to be polymerized by strong protonic acids such as phosphoric acid and hydrochloric acid. The cationic polymerization of $\varepsilon$-caprolactam was examined

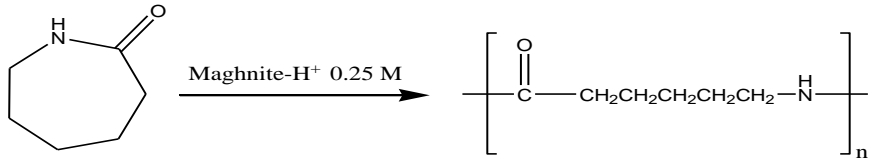

Scheme 1. Polymerization of $\varepsilon$-caprolactam by Maghnite- $\mathrm{H}^{+}$

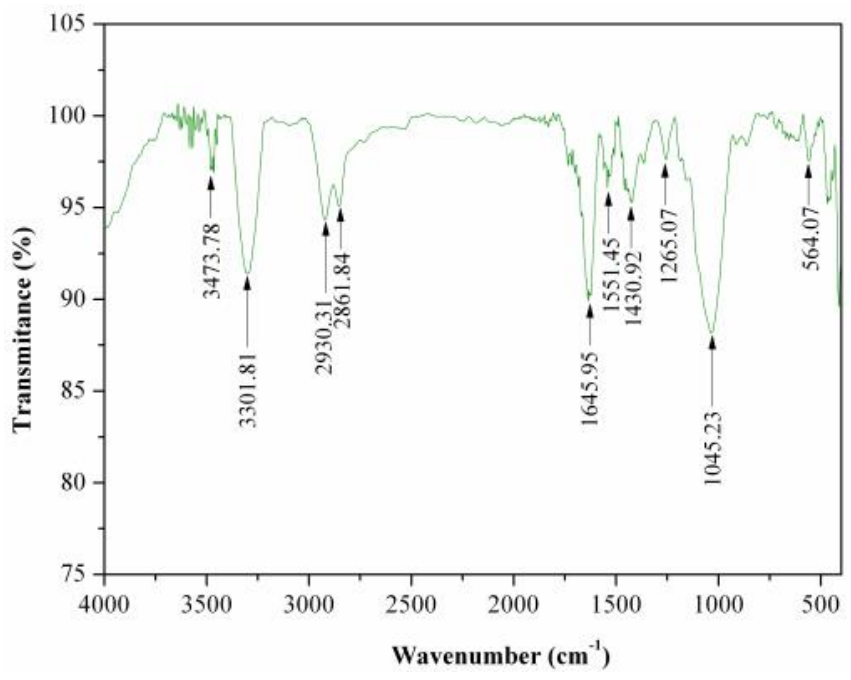

Figure 1. FT-IR spectrum of poly ( $\varepsilon$-caprolactam) product of the reaction

in the presence of Maghnite- $\mathrm{H}^{+}$powder in bulk at different temperatures (Scheme 1).

The IR measurements of product are in a good agreement with poly ( $\varepsilon$-caprolactam) structure (Figure 1). It is shown that the broad band at $3301.8 \mathrm{~cm}^{-1}$, usually assigned to the N$\mathrm{H}$ bending vibration in primary amine. The two bands at 2930.31 and $2861.84 \mathrm{~cm}^{-1}$ are assigned to the C-H stretching of the ethylene sequence [27]. Moreover, the absorbance at $1645.9 \mathrm{~cm}^{-1}$ related to $\mathrm{C}=\mathrm{O}$ amide $\mathrm{I}$ stretch, the intense band at $1045.23 \mathrm{~cm}^{-1}$ is assigned to the $\mathrm{C}-\mathrm{N}$ stretching of aliphatic amine and the combination absorbance of the $\mathrm{N}-\mathrm{H}$ and $\mathrm{C}-\mathrm{N}$ amide II stretch at $1551.4 \mathrm{~cm}^{-1}$ are clearly observed [28].

Figure 2 shows DSC heating scans for pure poly ( $\varepsilon$-caprolactam). The thermogram is characterized by only a peak at $219{ }^{\circ} \mathrm{C}$ during heating in the endothermic direction which corresponds to its fusion, and which is in agreement with data published earlier.

\subsection{Effect of Temperature}

Table 1 shows the experimental results for the $\varepsilon$-caprolactam polymerization initiated by Maghnite- $\mathrm{H}^{+}$at different temperatures. It was found that Maghnite- $\mathrm{H}^{+}$by itself possesses good activity as initiator for $\varepsilon$-caprolactam polymerization. The monomer conversion and 


\subsection{Kinetics and Mechanism of the Polymerization}

To get more insight into the $\varepsilon$-caprolactam polymerization by Maghnite- $\mathrm{H}^{+}$, the kinetics of e-caprolactam polymerization with Maghnite$\mathrm{H}^{+}$in bulk has been studied. Figure 5 shows that the polymerization is accurately first-order with respect to monomer.

In order to study polymerization mechanism, a poly ( $\varepsilon$-caprolactam) has been prepared and its ${ }^{1} \mathrm{H}$ and ${ }^{13} \mathrm{C}$ NMR spectra are shown in Figures 6 and 7. ${ }^{1} \mathrm{H}$ NMR spectra of poly $(\varepsilon$ caprolactam) showed a chemical shift of hydrogen-bonded protons at $8.5 \mathrm{ppm}$. Chemical shifts of the $\mathrm{CH}_{2}$ groups adjacent to the $\mathrm{NH}$ group and $\mathrm{CO}$ group were observed around 3.2 and

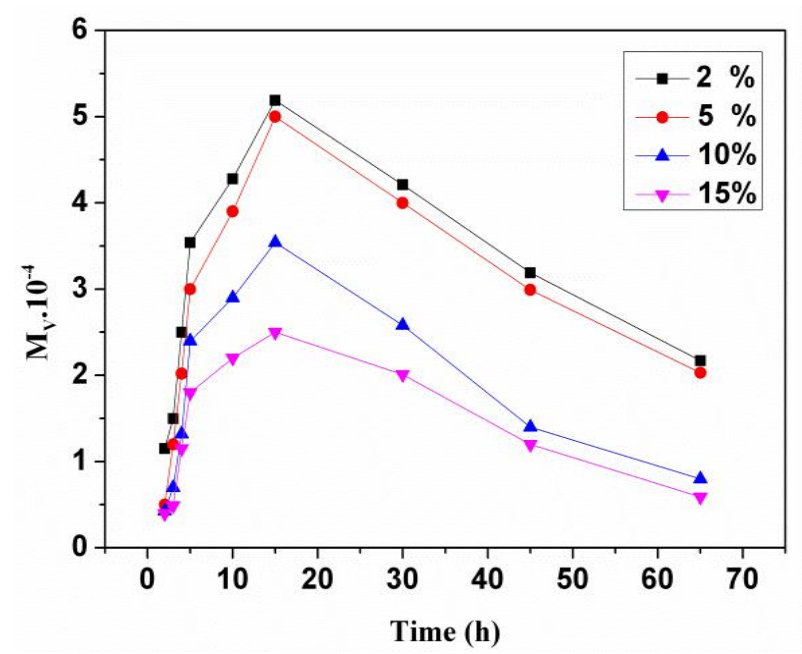

Figure 4. Effect of Maghnite- $\mathrm{H}^{+} /$Monomer weight ratio on the $M_{v}$ of the resulting polymers

Table 2. Kinetic evolution of $\varepsilon$-caprolactam polymerizationa initiated by Maghnite- $\mathrm{H}^{+}$

\begin{tabular}{cccc}
\hline $\begin{array}{c}\text { Time } \\
(\mathrm{h})\end{array}$ & $\begin{array}{c}\text { Conversion of } \\
\text { Monomer (wt \%) }\end{array}$ & $M_{V} \times 10^{-4}$ & $M_{w} / M_{n}$ \\
\hline 2 & 5.33 & 0.51 & 1.84 \\
3 & 26.54 & 1.29 & 1.61 \\
4 & 50.48 & 2.02 & 1.75 \\
5 & 67.25 & 3.11 & 1.81 \\
10 & 75.17 & 3.91 & 1.15 \\
15 & 93.13 & 5.19 & 1.80 \\
30 & 94.21 & 4.07 & 1.89 \\
45 & 94.86 & 2,99 & 1.85 \\
65 & 95.01 & 2,03 & 1.78 \\
\hline
\end{tabular}

a Maghnite- $\mathrm{H}^{+} / \varepsilon$-caprolactam weight ration $=5 \%$. Reaction temperature $250^{\circ} \mathrm{C}$
$2.3 \mathrm{ppm}$, respectively. Chemical shifts of the remaining aliphatic $\mathrm{CH}_{2}$ protons were observed around $1.35 \mathrm{ppm}\left({ }^{4} \mathrm{H}\right)$ and $1.1 \mathrm{ppm}\left({ }^{2} \mathrm{H}\right)$ [34]. ${ }^{13} \mathrm{C}$ NMR spectra gave a peak at $176.93 \mathrm{ppm}$ ppm. Chemical shifts of the $\mathrm{CH}_{2}$ groups adjacent to the $\mathrm{NH}$ group and $\mathrm{CO}$ group were observed around 3.2 and $2.3 \mathrm{ppm}$, respectively. Chemical shifts of the remaining aliphatic $\mathrm{CH}_{2}$ protons were observed around $1.35 \mathrm{ppm}\left({ }^{4} \mathrm{H}\right)$ and $1.1 \mathrm{ppm}\left({ }^{2} \mathrm{H}\right)$ [34]. ${ }^{13} \mathrm{C}$ NMR spectra gave a peak at $176.93 \mathrm{ppm}$ corresponding to the carbon of the amido group. The peaks at 39.90 and $35.83 \mathrm{ppm}$ correspond to the carbon atoms next to the amido groups (i.e. $-\mathrm{CONHC}^{*} \mathrm{H}_{2}-$ and $-\mathrm{C}^{*} \mathrm{H}_{2} \mathrm{CONH}-$, respectively), whereas the signals at $24.73,25.92$ and $28.80 \mathrm{ppm}$ belong to

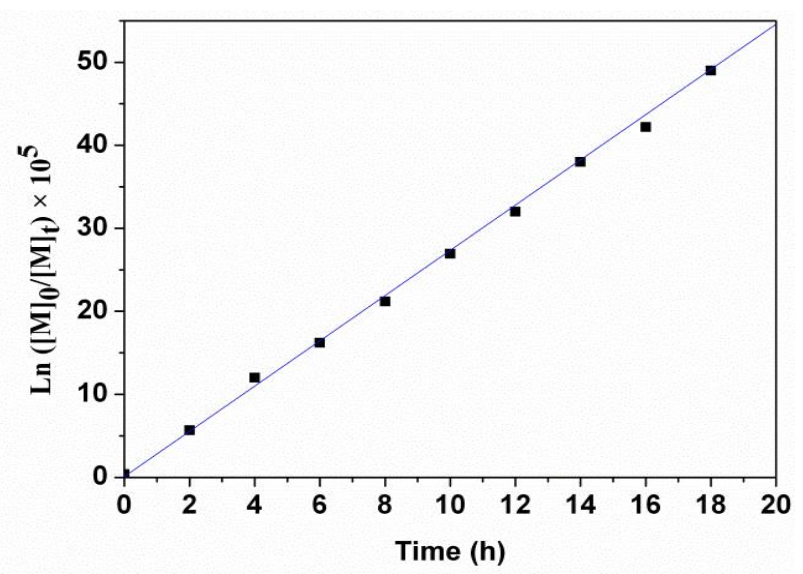

Figure 5. $\ln [M]_{\mathrm{o}} /[M]_{\mathrm{t}}$ as a function of time $(\mathrm{T}=$ $250 \circ \mathrm{C}$, Maghnite- $\mathrm{H}^{+} / \varepsilon$-caprolactam weight ratio $=5 \%)$
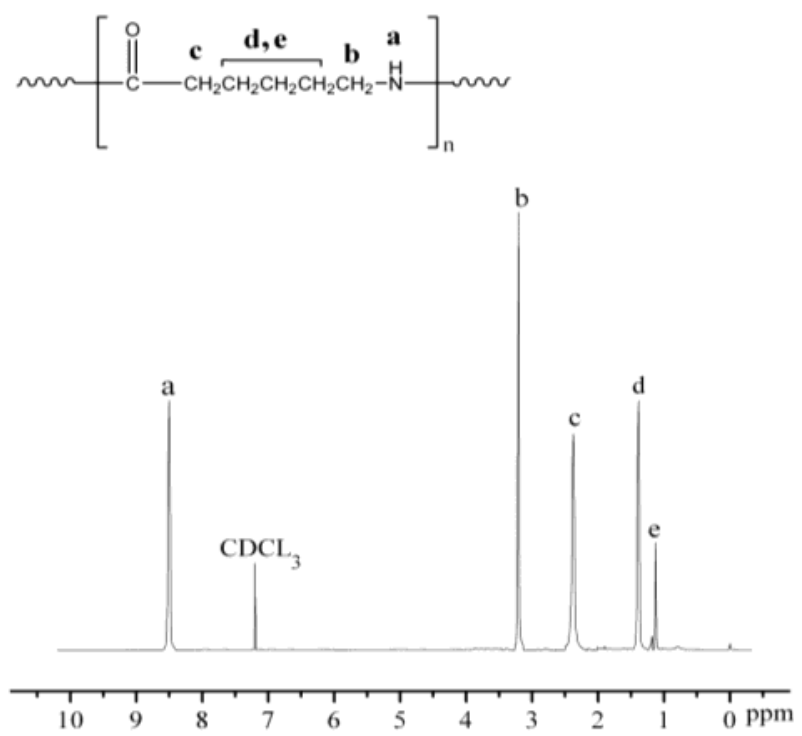

Figure 6. ${ }^{1} \mathrm{H}$ NMR spectra of poly ( $\varepsilon$ caprolactam) 


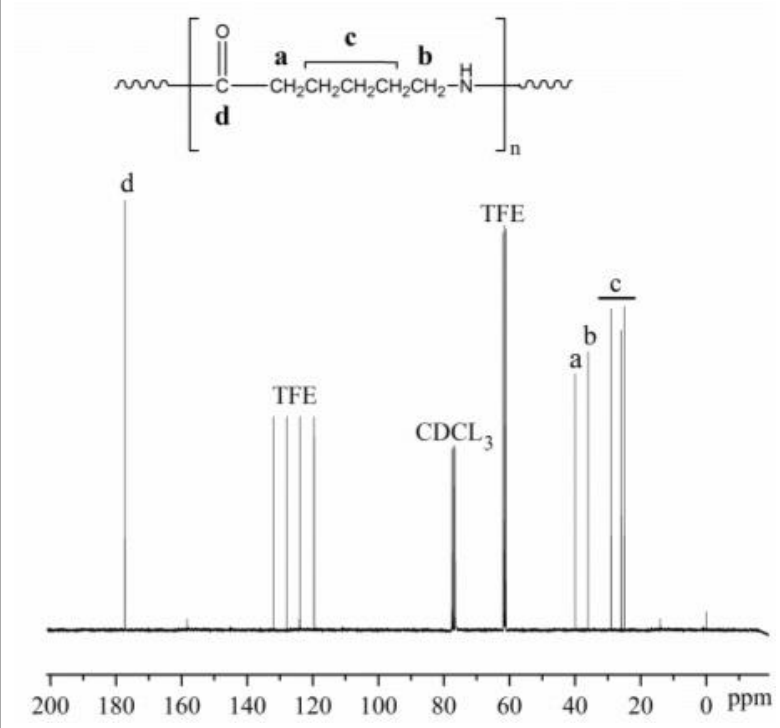

Figure 7. ${ }^{13} \mathrm{C}$ NMR spectrum of poly $(\varepsilon-$ caprolactam)

the remaining aliphatic carbon atoms $[35,36]$.

Results of ${ }^{1} \mathrm{H}$ and ${ }^{13} \mathrm{C}$ NMR indicate that the monomer inserts into the growing chains with the acyl-nitrogen bond scission rather than the break of alkyl-oxygen bond (Scheme 2).

\section{Conclusions}

Maghnite- $\mathrm{H}^{+}$, a proton exchanged montmorillonite clay was effective initiator for the ringopening polymerization of $\varepsilon$-caprolactam. It allowed to obtain high molecular weight poly ( $\varepsilon$ caprolactam). and a reaction yield particularly high (up to 95\%). The kinetics of polymerization demonstrated that the polymerization rate has the first-order in monomer concentration. Mechanism studies showed that monomer inserted into the growing chains with the acyloxygen bond scission rather than the break of alkyl-nitrogen bond. FTIR, ${ }^{1} \mathrm{H}$ NMR, and ${ }^{13} \mathrm{C}$ RMN spectroscopic studies did not indicate any significant difference in the structure between the obtained polymer and that obtained by strong acids. DSC showed a slight improvement in thermal stability compared to what is reported in the literature. In short, the optimal settings for the best results during the polymerization of $\varepsilon$-caprolactam by Maghnite$\mathrm{H}^{+}$were: $250{ }^{\circ} \mathrm{C}$ as temperature, $15 \mathrm{~h}$ as time and $5 \%$ as $\varepsilon$-caprolactam/Maghnite- $\mathrm{H}^{+}$weight ratio.

\section{References}

[1] Zimmerman, J., Mark, H.F., Bikales, N.M. (1988). In: Encyclopedia of Polymer Science<smiles>C=C[C@H](O)CN1CCCCCC1=O</smiles>

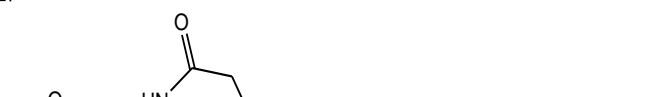

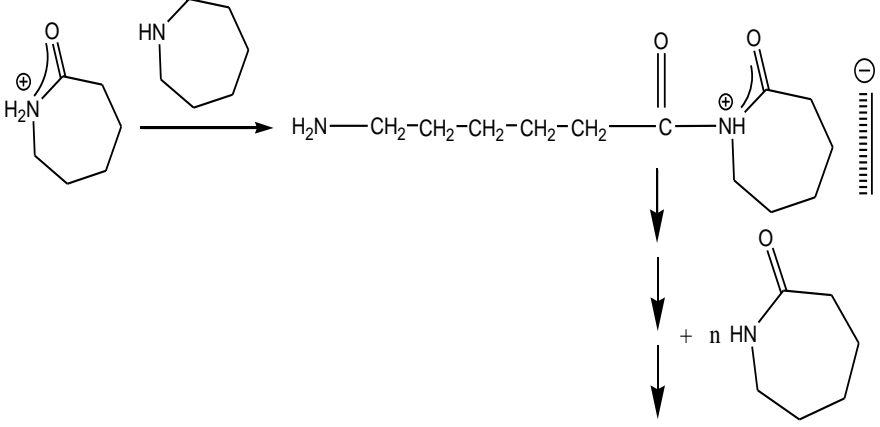<smiles>COCC1CCCC(=O)N1C(=O)CCCCCNC(C)C</smiles>

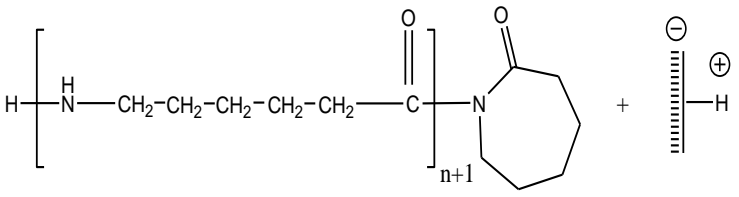

Scheme 2. Mechanism of $\varepsilon$-caprolactam polymerization catalysed by Maghnite- $\mathrm{H}^{+}$

and Engineering, vol. 6: Wiley: 802-839, New York.

[2] Bergshoef, M.M., Vancso, G.J. (1999). Transparent Nanocomposites with Ultrathin, Electrospun Nylon-4,6 Fiber Reinforcement. Advanced Materials. 11: 1362-1365.

[3] Zhi, Y.W., Wei, X., Jin K.X., Yao, C.L., Qian, X.W., Wei, J.X. (2008). Flame retardant polyamide 6 by in situ polymerization of $\varepsilon$ caprolactam in the presence of melamine derivatives. Chinese Chemical Letters, 19: 241244.

[4] Kudva, R. A., Keskkula, H., Paul, D. R. (2000). Properties of Compatibilized Nylon 6/ ABS Blends: Part 1: Effect of ABS Type. Polymer, 41: 225-237.

[5] Kohan, M.I. (Editor) (1995). Nylon plastics hand book. New York: Hanser.

[6] Van Der Want, G. M., Kruissink, CH.A. (1959). A non-hydrolytic polymerization of $\epsilon$ caprolactam. The polymerization initiated by hydrogen chloride. Journal of Polymer Science. 35: 119-138.

[7] Doubrovszky, S., Geleji, F. (1965). The International Symposium. Preprint P 336. 
[8] Schlack, P. (1965). Chemiefasern, 15: 64.

[9] Mattiussi, A., Gechele, G.B. (1965). Molecular weight distribution in hydrolytic polycaprolactam. European Polymer Journal. 1: 147.

[10] Stea, G., Gechele, G.B. (1965). Molecular weight distribution in anionic polycaprolactam. European Polymer Journal. 1: 213-225.

[11] Burnett, G.M., Hay, J.N., McArthur, A.J. (1966). Paper read at the Symposium on the Chemistry of Polymerization Process, London. S.C.I. Monograph No. 20.

[12] Geleji, F., Szafner, A., Holly, Z., Szollar, L. (1960). International Symposium on Macromolecular Chemistry, 487. Moscow.

[13] Geleji, F., Szafner, A. (1962). On the mechanism of polymerization of caprolactam catalyzed by phosphoric acid. II. Journal of Polymer Science. 58: 955-975.

[14] Geleji, F., Szafner, A., Holly, Z. (1963). Chemifaser Symposium, 273. Berlin.

[15] Reinisch, G., Gohlke, U. (1968). TextilTechn, 19: 87.

[16] Reinisch, G., Gohlke, U. (1972). Textiltechn, 23: 415 .

[17] Mizerovskh, L.N., Silant'eva, V.G., Paikachev, Y.S., Bykov, A.N. (1976). Vysokomol. Soyed. 5: 1082-1088.

[18] Gechele, G.B., Stea, G., Manescalchi, F. (1968). Cationic polymerization of caprolactam. European Polymer Journal, 4: 505-513.

[19] Harrane, A., Meghabar, R., Belbachir, M. (2002). A Protons Exchanged Montmorillonite Clay as an Efficient Catalyst for the Reaction of Isobutylene Polymerization. International J.ournal of Molecular Sciences. 3: 790-800.

[20] Ferrahi, M.I., Belbachir, M. (2003). Polycondensation of Tetrahydrofuran with Phthalic Anhydride Induced By a Proton Exchanged Montmorillonite Clay. International Journal of Molecular Sciences. 4: 312-325.

[21] Brown, D.R., Carpathica, G. (1994). Clays as catalyst and reagent supports. Geologica Carpathica Ser. Clays, 45: 45-56.

[22] Laszlo, P. (1987). Preparative Chemistry Using Supported Reagents, Academic Press, San Diego.

[23] Belbachir, M., Bensaoula, A. (2001). US Patent. No 6, 274,527B1.

[24] Wiloth, F. (1958). Makromolek. Chem, 27: 37.

[25] Ballantine, J.A., Davies, M., Purnell, H. Rayanakorn, M., Thomas, J.M., Williams K.J. (1981). J. C. S. Chem. Commun, 427.
[26] Hojabri, F. (1971). Gas-phase catalytic alkylation of aromatic hydrocarbons. Journal of Applied Chemistry and Biotechnology. 21: 87-89.

[27] Iwamoto, R., Murase, H. (2003). Infrared spectroscopic study of the interactions of nylon-6 with water. Journal of Polymer Science Part B: Polymer Physics. 41: 1722-1729.

[28] Jianxin, T., Nongyue, H., Libo, N., Pengfeng, X., Hong, C. (2004). Hydrolysis of microporous polyamide- 6 membranes as substrate for in situ synthesis of oligonucleotides. Surface Science, 550: 26-34.

[29] Harrane, A., Meghabar, R., Belbachir, M. (2006). Kinetics of the ring opening polymerization of $\varepsilon$-caprolactone catalysed by a proton exchanged montmorillonite clay. Reactive \& Functional Polymers, 66: 1696-1702.

[30] Odian, G. (1994). La Polymerisation: principes et Applications, Ed. Technica, 222-226. New York.

[31] Zhong, Z.H., Ankone, M.J., Dijkstra, P.J., Birg, C., Feijenl, M.W. (2001). Calcium methoxide initiated ring-opening polymerization of $\varepsilon$-caprolactone and L-lactide. Polymer Bulletin, 46: 51-57.

[32] Deshayes, G., Mercier, F.A., Degee, P., Verbruggen, I., Biesemans, M., Willem, R., Dubois, P. (2003). Mechanistic Study of $\mathrm{Bu}_{2} \mathrm{SnCl}_{2}$-Mediated Ring-Opening Polymerization of $\varepsilon$-Caprolactone by Multinuclear NMR Spectroscopy. Chemistry A European Journal. 9: 4346-4352.

[33] Luo, Y., Yao, Y., Shen, Q., Sun, J., Weng, L. (2002). Synthesis, characterization of homoleptic lanthanide amidinate complexes and their catalytic activity for the ring-opening polymerization of $\varepsilon$-caprolactone. Journal of Organometallic Chemistry, 662: 144-149

[34] Deshayes, G., Delcourt, C., Verbruggen, I., Trouillet-Fonti, L., Touraud, F., Fleury, E., Degée, P., Destarac, M., Willem, R., Dubois, P. (2008). Activation of the hydrolytic polymerization of $\varepsilon$-caprolactam by ester functions: Straightforward route to aliphatic polyesteramides. Reactive \& Functional Polymers, 68: 1392-1407.

[35] Davis, R.D., Jarrett, W.L., Mathias, L.J. (2001). Solution ${ }^{13} \mathrm{C}$ NMR spectroscopy of polyamide homopolymers (nylons 6, 11, 12, 66, 69, 610 and 612) and several commercial copolymers. Polymer, 42: 2621-2626.

[36] Rick, D.D., Jeffery, W.G., David, L.V., (2003). Processing degradation of polyamide 6/ montmorillonite clay nanocomposites and clay organic modifier. Polymer Degradation and Stability, 79: 111-1121. . 